\title{
Perceptions of Social Media Use to Augment Health Care Among Adolescents and Young Adults With Cystic Fibrosis: Survey Study
}

Ryan C Perkins ${ }^{1,2}$, MD; Rachel Gross ${ }^{1}$, BS; Kayla Regan ${ }^{1}$, BA; Lara Bishay ${ }^{3}$, MD, MPH; Gregory S Sawicki ${ }^{1}$, MD, $\mathrm{MPH}$

\footnotetext{
${ }^{1}$ Division of Pulmonary Medicine, Boston Children's Hospital, Boston, MA, United States

${ }^{2}$ Division of Pulmonary and Critical Care Medicine, Brigham and Women's Hospital, Boston, MA, United States

${ }^{3}$ Division of Pulmonary and Sleep Medicine, Children's Hospital of Los Angeles, Los Angeles, CA, United States
}

\section{Corresponding Author:}

Ryan C Perkins, MD

Division of Pulmonary Medicine

Boston Children's Hospital

300 Longwood Avenue

Boston, MA, 02115

United States

Phone: 16173551900

Email: ryan.perkins@ @ childrens.harvard.edu

\section{Abstract}

Background: For individuals with cystic fibrosis (CF), adolescence and young adulthood are times of significant vulnerability and have been associated with clinical and psychosocial challenges. Social media may offer innovative care delivery solutions to address these challenges.

Objective: This study explored motivations and attitudes regarding current social media use and preferences for a social media platform in a sample of adolescents and young adults (AYA) with CF.

Methods: A cross-sectional survey was administered to 50 AYA with CF followed at a large pediatric-adult CF center. The survey included questions regarding social media platform utilization, attitudes toward general and CF-specific online activities, and preferences for a CF-specific care delivery platform.

Results: YouTube, Snapchat, and Instagram were the most commonly used social media platforms. AYA with CF do not report routinely using social media for health-related information acquisition, social support, or help with adherence. However, their perceptions of social media utilization and preferences for platform development suggest interest in doing so in the future.

Conclusions: AYA with CF use social media and expressed interest in the development of a social media platform. Platform development will allow for gaps in health care delivery to be addressed by improving social support and adherence while augmenting current methods of health information acquisition.

(JMIR Pediatr Parent 2021;4(3):e25014) doi: 10.2196/25014

\section{KEYWORDS}

cystic fibrosis; social media; mobile health; adherence; adolescents; young adults

\section{Introduction}

\section{Background}

Cystic fibrosis (CF) is the most common life-shortening genetic disease in White people in the United States [1,2]. The CF care model, which focuses on coordinated, multidisciplinary care delivery in specialized $\mathrm{CF}$ care centers, has contributed to improvements in clinical outcomes. $\mathrm{CF}$ was previously a disease with nearly uniform death in childhood but improved care has

resulted in a median predicted survival age of patients of 46.2 years [1]. Current clinical guidelines for patient care recommend patients be evaluated quarterly and more frequently during the first year of life or with the illness [3-5].

Despite care delivery improvements, adolescents and young adults (AYA) with CF still face significant vulnerabilities. Studies in CF adolescents have revealed reductions in medication adherence [6], reductions in lung function despite more aggressive management and implementation of new therapies [7], increased symptom burden [8], and development 
or acceleration of CF-related complications [8]. Individuals with $\mathrm{CF}$ often face significant feelings of isolation [6,9] and are unable to congregate in typical support group structures [10] due to infection control guidelines [11]. These issues remain largely unaddressed by the current care delivery paradigm. Novel approaches to health care delivery are needed during this vulnerable time to support AYA with $\mathrm{CF}$.

\section{Prior Work}

Electronic health applications such as telehealth, mobile health (mHealth), and social media may be beneficial in addressing gaps in the current care delivery paradigm. Previously, mHealth and social media have been proposed as opportunities to engage AYA and augment care delivery [12,13]. These platforms may allow for improvements in social support, provide innovative networking opportunities for patients and their care team, and provide novel methods to improve disease self-management and adherence.

Previous mHealth studies have been carried out across diseases and were found to improve clinical outcomes, medication adherence, and self-monitoring in solid organ transplantation [14-17], essential hypertension [18,19], congestive heart failure [20], type 2 diabetes [21], and coronary artery disease [22]. However, not all have shown a clinically significant impact or improvements in adherence [23]. Within CF, a focus group study suggested implementation of a web-enabled cellphone would improve knowledge, provide social support, and result in improved adherence [24]. Another study exploring mHealth preferences noted the importance of automated assistance with disease management, improving communication with the multidisciplinary care team, and facilitating socialization with others with CF [25]. Although mHealth applications have been shown to have high acceptability [26], their long-term uptake remains problematic [13].

Social media has been used in other pulmonary diseases to understand patient experience [27], to characterize patient preferences for information acquisition [28], and to improve self-management and social support [29]. Social media has been leveraged to develop a disease-specific social network for chronic obstructive pulmonary disease to address loneliness and improve social support [30,31]. However, studies investigating social media usage in AYA with CF are lacking. Facebook has been described as a method for information dissemination by a large adult $\mathrm{CF}$ center in the United Kingdom [32]. Facebook, Facetime, and Instagram were described in a small qualitative study of 9 Canadian AYA with $\mathrm{CF}$ as a method to reduce social isolation and improve support [33]. A more recent study assessed 66 adults with $\mathrm{CF}$ or direct connection to CF (caregiver, significant other, immediate family member) regarding social media usage. The study found $98 \%$ of respondents used social media, with $96 \%$ of respondents using an online forum (Facebook, cysticfibrosis.com, healingwell.com). The study however had significant limitations in that it only captured adults, surveyed predominantly those without CF (39\% had CF), and suffered from ascertainment bias as recruitment was performed online via email, on social media websites, and using CF dedicated message boards [34]. Larger survey studies to assess preferences for a CF-related social media platform, CF-related social media usage, perceptions regarding online $\mathrm{CF}$ health activities, and current social media platform usage among AYA with CF are lacking. It is crucial that patient motivations for social media usage and preferences for such platforms are explored to inform care delivery.

\section{Goal of This Study}

The goal of this study was to characterize current social media utilization patterns and attitudes, motivations for social media utilization, and preferences for social media platform development in AYA with CF.

\section{Methods}

\section{Recruitment}

We performed a cross-sectional survey of AYA with CF receiving care at a large pediatric-adult $\mathrm{CF}$ center. Participants were eligible for enrollment if they were aged between 13-30 years and diagnosed with CF. Patients were only excluded if they had previously received a solid organ transplantation. Participants were recruited from the ambulatory CF clinic and during hospital admissions on the inpatient pulmonary service from October-December 2018. Informed consent/assent was obtained electronically, and the study was approved by the institutional review board at Boston Children's Hospital (IRB-P0025949). The survey was administered by iPad using an online link to the survey.

\section{Clinical Measurements}

Clinical parameters including percent predicted forced expiratory volume in 1 second (ppFEV1), hospitalizations over the last year, BMI, cystic fibrosis-related diabetes status, age, and gender were abstracted from the medical record.

\section{Survey Battery}

The survey included 60 multiple choice questions (Multimedia Appendix 1) and explored general health/demographics (11 questions), potential components to include in a social media platform (12 questions), CF-related social media usage (11 questions), perceptions regarding online $\mathrm{CF}$ health activities (16 questions), and current social media platform utilization (10 questions). The topics included in the instrument were developed on the basis of previous research and scholarship surrounding social media utilization in CF [35]. The survey was piloted with 3 patients. Responses were reviewed to ensure appropriate question branching logic based on patient responses. Study data were collected and managed using Research Electronic Data Capture (REDCap) tools [36,37].

\section{Data Analysis}

Descriptive statistics were used to analyze respondent demographics, social media utilization, attitudes/perceptions/motivations during utilization, and preferred components of a social platform. Respondent Likert scale ratings for social media platforms and attitudes during social media utilization were operationalized in the following way: " $1=$ never" and "2=rarely" were categorized together and " $3=$ sometimes" and "4=often" were categorized together. 
Additional questions for perceptions/motivations during social media utilization were operationalized as follows: " $1=$ strongly disagree" and "2=disagree" were categorized together and " $3=$ agree" and " $4=$ strongly agree" were categorized together. Finally, Likert scale ratings for components of social media platforms were operationalized in the following way: " $1=$ not at all important" and " $2=$ somewhat unimportant" were categorized together and " $3=$ somewhat important" and " $4=$ very important" were categorized together. The associations of respondents' social media utilization, attitudes/perceptions/motivations of current social media utilization, and component preferences for a social media platform with clinical parameters were assessed via chi-square test, paired $t$ test, or analysis of variance, as appropriate. All analyses were conducted using STATA (version 15.1; StataCorp LLC).

\section{Results}

During the study period, 147 patients met the eligibility requirements for inclusion in the study. Of these, 80 patients were not approached as they cancelled their appointment, were felt to be inappropriate for research by their primary pulmonologist, or finished their clinic visit before the research team could approach them. Of the 67 remaining patients, 17 declined to participate in the study. A total of 50 AYA completed the survey (Table 1).

Table 1. Cohort characteristics.

\begin{tabular}{|c|c|}
\hline Characteristics of participants & Values \\
\hline \multicolumn{2}{|l|}{ Gender, n (\%) } \\
\hline Entire cohort & $50(100)$ \\
\hline Males & $25(50)$ \\
\hline Females & $25(50)$ \\
\hline Age $(n=50)$, mean/range (SD) & $19.8 / 13-30(5.2)$ \\
\hline \multicolumn{2}{|l|}{ Racial/ethnic background, ${ }^{\mathrm{a}} \mathrm{n}(\%)$} \\
\hline White & $49(98)$ \\
\hline Latino & $2(4)$ \\
\hline Black & $1(2)$ \\
\hline Other & $1(2)$ \\
\hline \multicolumn{2}{|l|}{ Highest education level achieved, n (\%) } \\
\hline Some high school or less & $22(44)$ \\
\hline High school or General Educational Development (GED) & $4(8)$ \\
\hline Some college & $6(12)$ \\
\hline College/vocational degree & $13(26)$ \\
\hline Professional/graduate degree & $5(10)$ \\
\hline \multicolumn{2}{|l|}{ Current health status, n (\%) } \\
\hline Excellent & $9(18)$ \\
\hline Very good/good & $32(64)$ \\
\hline Fair/poor & $9(18)$ \\
\hline \multicolumn{2}{|l|}{ Cystic fibrosis severity, n (\%) } \\
\hline Mild & $24(48)$ \\
\hline Moderate & $23(46)$ \\
\hline Severe & $3(6)$ \\
\hline Cystic fibrosis-related diabetes ${ }^{\mathrm{b}}(\mathrm{n}=50), \mathrm{n}(\%)$ & $9(18)$ \\
\hline $\mathrm{BMI}^{\mathrm{b}}(\mathrm{n}=50)$, mean/range $(\mathrm{SD})$ & 21.3/15.4-35.9 (3.6) \\
\hline Percent predicted forced expiratory volume in 1 second $^{\mathrm{b}}(\mathrm{n}=50)$, mean/range (SD) & $77.2 / 26-126(23.5)$ \\
\hline Hospitalizations $^{\mathrm{b}}(\mathrm{n}=50)$, mean/range $(\mathrm{SD})$ & $1.4 / 0-8(1.9)$ \\
\hline
\end{tabular}

${ }^{\mathrm{a}}$ Respondents instructed to select all racial/ethnic backgrounds with which they identify.

${ }^{\mathrm{b}}$ Abstracted from the electronic medical record. 
Components to include in a social platform for AYA with CF are noted in Figure 1. Respondents conveyed that a platform should include elements to help with care delivery. Overall, 44 of $49(90 \%)$ endorsed that it was important to include a forum to provide online support for people with $\mathrm{CF}, 82 \%$ (41/50) requested accountability group creation where participants can post about self-care, and 76\% (38/50) desired reminders to help with CF self-care. In addition, respondents also expressed strong support for including elements for acquisition of accurate health information. For example, 92\% (45/49) wanted medical information available that came from well-known sources such as the CF Foundation and $90 \%$ (45/50) felt it was important to include links to specific $\mathrm{CF}$ topics.

Figure 1. Potential components to include in a CF social media platform.

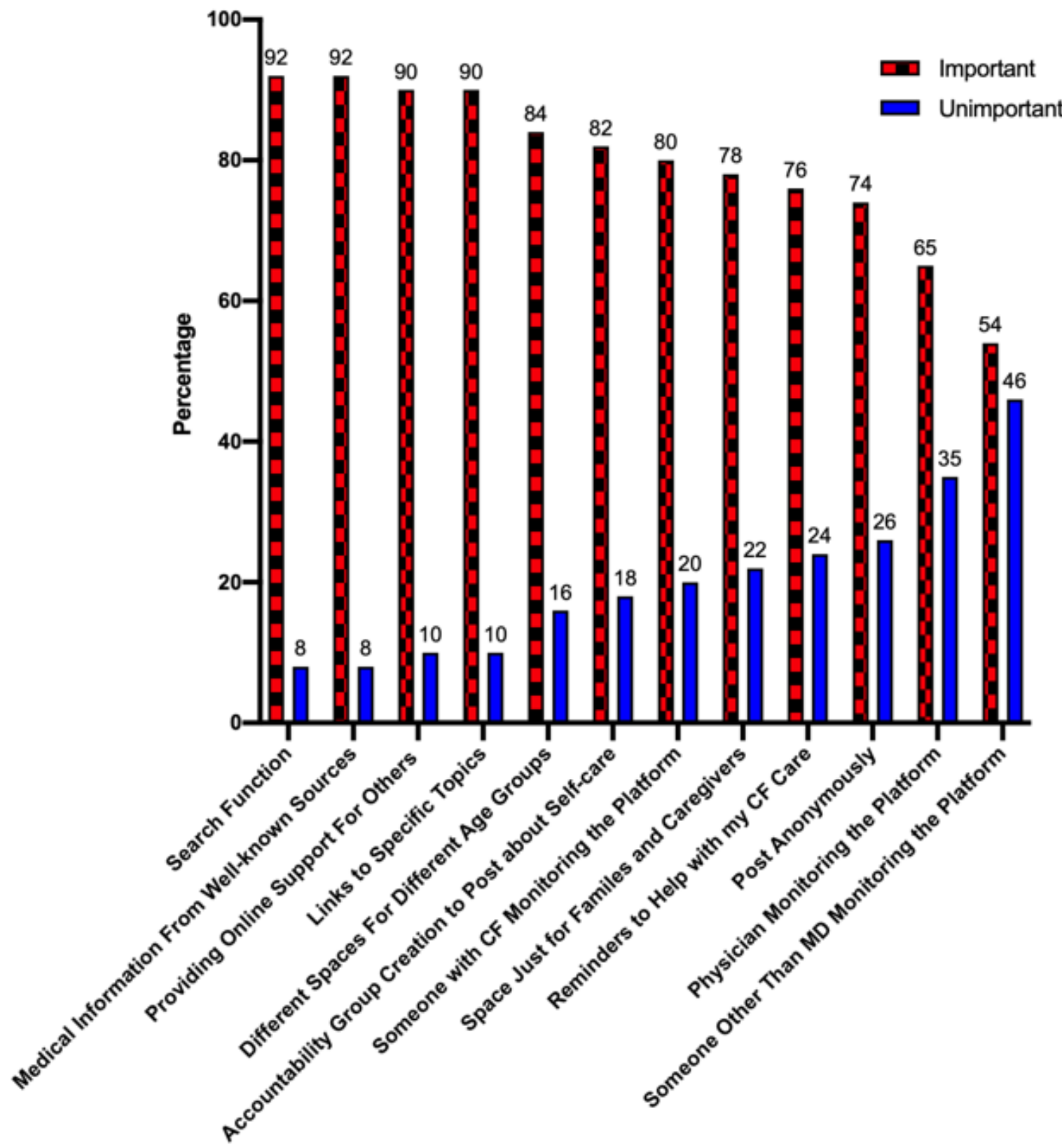

Current CF-related social media usage is shown in Figure 2. When evaluating current online health-related activities, 50\% (25/50) endorsed reading about CF-related information online "sometimes" or "often." These respondents were older (mean age of readers 22 years versus 17.6 years for nonreaders; $P=.002)$ and were more likely to be female (64\% female readers versus $36 \%$ male readers; $P=.05)$. In addition, $42 \%(21 / 50)$ of respondents learned about other people's experiences with $\mathrm{CF}$ online. Only $24 \%$ of respondents (12/50) endorsed interacting with other patients with $\mathrm{CF}$ online and even fewer $(7 / 50,14 \%)$ sought support from other people with CF online. 
Figure 2. Cystic fibrosis-related social media use.

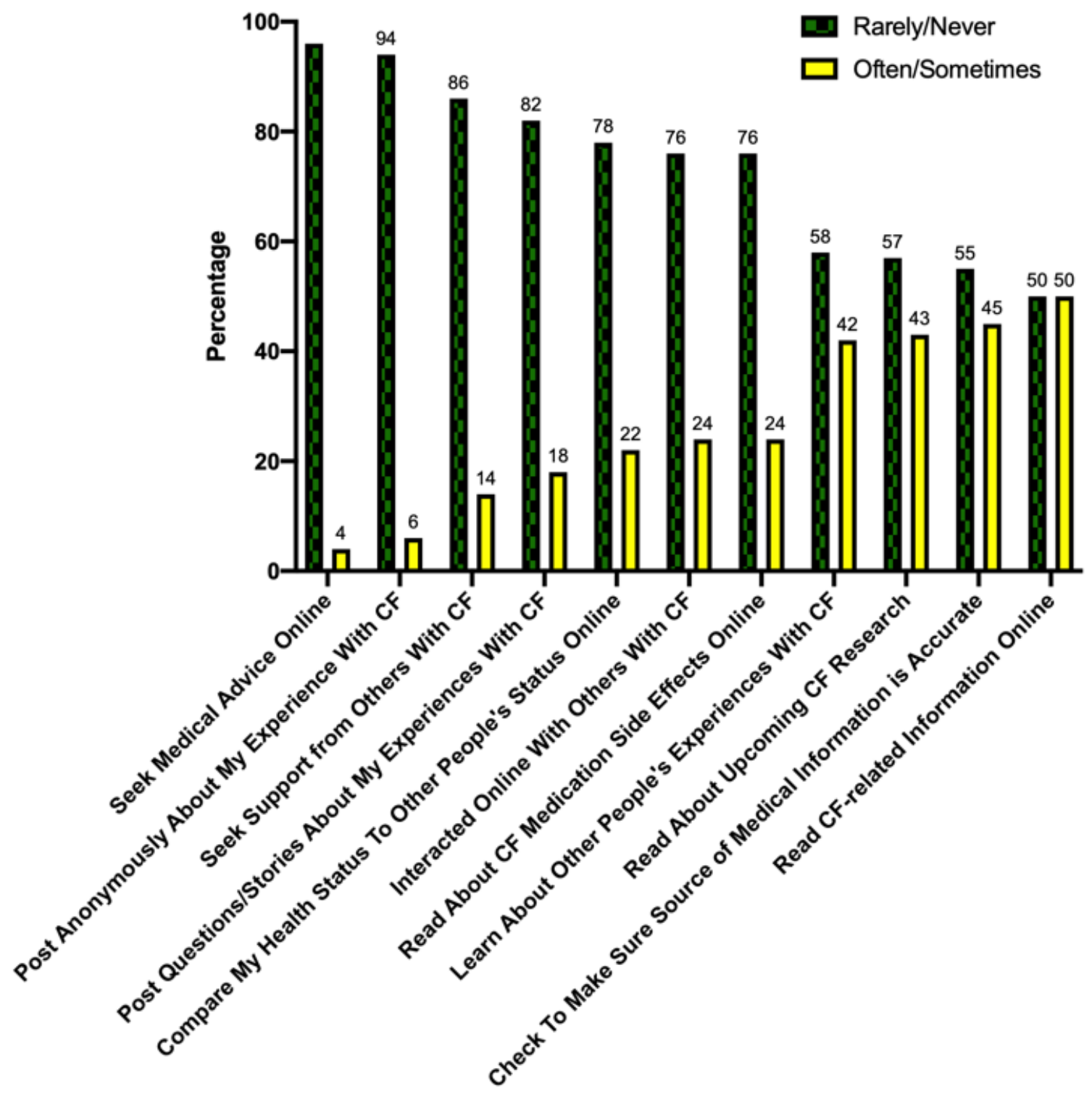

Although only a minority of respondents reported current social media use for online CF-related health activities, their perceptions regarding the potential uses for online CF-related health activities were different (Table 2). For example, only $42 \%(21 / 50)$ endorsed learning about other people's experiences with CF online. However, 77\% (37/48) reported they "agree" or "strongly agree" that they feel inspired by stories of other people with CF online (37/48) and 65\% (32/49) noted that they wanted to motivate and inspire others with $\mathrm{CF}$. 
Table 2. Perception regarding online cystic fibrosis health activities.

\begin{tabular}{|c|c|c|}
\hline Perceptions & $\begin{array}{l}\text { Strongly } \\
\text { agree/agree, n (\%) }\end{array}$ & $\begin{array}{l}\text { Strongly disagree/dis- } \\
\text { agree, } \mathrm{n}(\%)\end{array}$ \\
\hline Medical information online should come from a source like the CF Foundation $(n=49)$ & $45(92)$ & $4(8)$ \\
\hline Medical information should be from a source like a doctor $(n=50)$ & $45(90)$ & $5(10)$ \\
\hline I feel inspired by stories of other people with CF online $(n=48)$ & $37(77)$ & $11(23)$ \\
\hline It is important to me to keep my privacy online $(\mathrm{n}=50)$ & $35(70)$ & $15(30)$ \\
\hline I want to inspire and motivate others with $\mathrm{CF}$ online $(\mathrm{n}=49)$ & $32(65)$ & $17(35)$ \\
\hline Online bullying or trolling is a serious risk $(\mathrm{n}=50)$ & $32(64)$ & $18(36)$ \\
\hline I feel motivated to perform my own self-care when I see other people with $\mathrm{CF}$ online $(\mathrm{n}=49)$ & $31(63)$ & $18(37)$ \\
\hline I feel less alone when I read stories about other people's struggles with CF ( $\mathrm{n}=48$ ) & $27(56)$ & $21(44)$ \\
\hline Medical information should come from a source like pharmaceutical companies $(n=50)$ & $27(54)$ & $23(46)$ \\
\hline I feel supported by other people with CF online $(n=48)$ & $23(48)$ & $25(52)$ \\
\hline I wish I could meet other people with CF in real life after meeting them online $(n=48)$ & $22(46)$ & $26(54)$ \\
\hline I feel sad or scared when I learn about other people's CF stories online $(n=49)$ & $13(27)$ & $36(73)$ \\
\hline I feel uncomfortable when comparing my health status to those of others with CF online $(n=49)$ & $12(24)$ & $37(76)$ \\
\hline I avoid other people with $\mathrm{CF}$ online $(\mathrm{n}=49)$ & $7(14)$ & $42(86)$ \\
\hline I have met other people with $\mathrm{CF}$ in real life after meeting them online $(\mathrm{n}=48)$ & $6(13)$ & $42(87)$ \\
\hline I feel less motivated to perform my own self-care when I interact with others with CF online ( $n=48)$ & $2(4)$ & $46(96)$ \\
\hline
\end{tabular}

Nearly two-thirds $(31 / 49,63 \%)$ endorsed feeling more motivated to perform their own self-care when interacting with others with $\mathrm{CF}$ online. In addition to the positive impact on motivation and inspiration, 56\% (27/48) noted feeling less alone when they read stories about other people's struggles with CF. Nearly half $(23 / 48,48 \%)$ of respondents noted feeling supported by other people with CF online. Only 14\% (7/49) reported that they actively avoid other people with CF online. When considering the potential negative ramifications of online interaction, $27 \%$ (13/49) endorsed feeling sad or scared when learning about other people's CF stories online, 24\% (12/49) felt uncomfortable when comparing their health status to those of others with $\mathrm{CF}$ online, and $4 \%$ (2/48) felt less motivated to perform self-care when interacting with others with $\mathrm{CF}$ online. Regarding these perceptions, women were more likely to feel motivated to perform self-care ( $83 \%$ of females [20/24] versus $44 \%$ of males [11/25]; $P=.004$ ), feel less alone (71\% of females [17/24] versus $42 \%$ of males [10/24]; $P=.04)$, and endorse feeling supported by others with $\mathrm{CF}$ online (63\% of females [15/24] versus $33 \%$ of males [8/24]; $P=.04)$.

Social media platform utilization among AYA with CF is shown in Figure 3. Respondents who endorsed YouTube usage were younger (mean age 19.1 years in users versus 23.8 years in nonusers; $P=.02$ ). In contrast, Facebook usage was higher among older respondents (mean age 21.2 years in users versus 18.1 years in nonusers; $P=.03$ ). Female respondents had higher usage of Instagram compared to males ( $92 \%$ of females [23/25] versus $60 \%$ of males [15/25]; $P=.008)$. 
Figure 3. Social media platform use among adolescents and young adults with CF. CFF: Cystic Fibrosis Foundation.

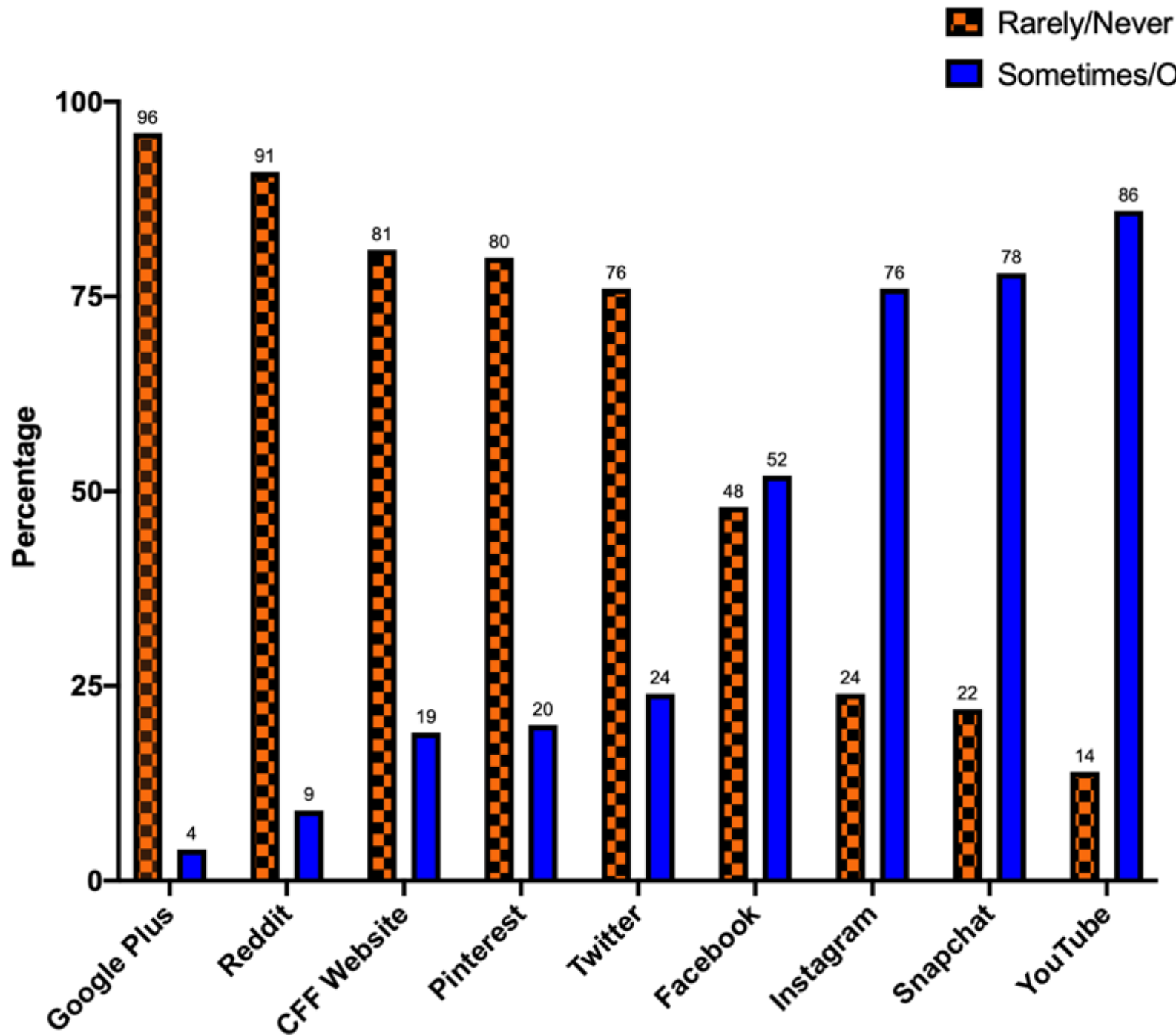

\section{Discussion}

\section{Principal Findings}

This study highlights several potential avenues for CF social media platforms to improve care delivery for AYA with CF. Social support was a theme routinely identified by study participants as a potential area for exploration. Our study indicated that AYA with CF do not currently use social media for social interaction or support. This may be due to lacking a dedicated platform for interaction, not knowing others with CF, concerns about privacy of identity or medical-related information, or concerns for potential negative emotional consequences that may develop from interactions. Despite not currently using social media platforms for interaction or support, respondents generally expressed encouraging perceptions (feel more supported, feel less alone, feel inspired) regarding their attitudes after interacting with others with $\mathrm{CF}$. This theme was also supported by respondents' preferences for components in a CF social media platform. Their desire for the creation of online forums to provide support to others and the creation of accountability groups suggest participants' perceived importance of connectedness and communication with one another. It should be noted that nearly one-fourth of respondents did experience feelings of sadness, being scared, or discomfort as a result of social interactions online. This suggests that a CF-centered platform may not be an appropriate social support structure for all, particularly those with higher risk of mental health concerns. One previous mHealth study did anticipate the need for mental health resources, medical supervision, and online moderators to provide guidance and support to address this concern [24].

There is growing evidence demonstrating the importance of social support among patients with $\mathrm{CF}$ and their health-related outcomes. A longitudinal survey study of 250 adults with CF explored this relationship and found fewer self-reported mental and physical health symptoms, digestive symptoms, and eating disturbances. Social support was associated with improved emotional, social, and role functioning, vitality, and body image. Those who reported more social support perceived less treatment burden and experienced better overall perceptions of their health [38]. Another cross-sectional study of 233 adults with CF highlighted the association of gender on perceived social support in adults with $\mathrm{CF}$, with females perceiving greater levels of support [39]. Likewise, our study also revealed a gender disparity, with females perceiving a greater level of support, increased motivation to perform self-care, and feeling less isolated after interacting with others compared to males in our 
study. These studies highlight the potential role for a CF social media health platform in improving care delivery through augmenting social support and improving health outcomes.

Respondents to the survey also felt a CF social platform could be used to improve motivations for adherence. Participants generally endorsed increased motivation to perform self-care after interacting with others with CF. It is plausible that increased emotional support could lead to improved motivation among respondents and ultimately to an increase in adherence with performing self-care. Increased social interaction did not appear to have a negative reported effect on adherence. Respondents' desires for potential components of an electronic platform (developing accountability groups, reminders to help with self-care) also suggest their interest in improving care delivery through virtual community building while also allowing for individualizing adherence assessments. The respondents' motivations and desires are congruent with interventions proposed to improve adherence through the implementation of patient-centered treatment plans, harnessing technology and application development to increase patient motivation and virtual support, and improving the CF health service model to address individual barriers to adherence [2]. These motivations and desires suggest the possible positive implications that a $\mathrm{CF}$ social media health platform can have in improving care delivery through improved patient adherence.

This study indicated that AYA with CF do commonly use social media. Despite this, the majority of respondents do not currently use social media platforms for health-related information acquisition (read about upcoming research, read CF-related information online, read about medication side effects). Their perceptions about what components are important to include in a social media platform suggest their interest in health-related information acquisition online as evidenced by the perceived importance of including a search function, medical information coming from well-known sources, and links to CF-specific topics. It is unclear if participants do not currently perform these actions because they are unaware of where to acquire this information or if they do not trust social media platforms as sources of information. The latter is consistent with a cross-sectional survey of 204 AYA patients without CF in which only $25 \%$ felt social media provided useful health information [40]. The Cystic Fibrosis Foundation website provides robust information about $\mathrm{CF}$, medications, and upcoming research that is evidence- and consensus-based, although our study indicates that AYA rarely use this resource.

\section{Limitations of Study}

This study has several limitations. First, participants in our study were varied in age, with the majority of respondents under the age of 21. This age distribution may skew the cohort sample and make results less generalizable to adults with CF. However, all of the respondents would be potential users of a future social media platform. Second, though small, our study represents one of the largest samplings to date of AYA patients with CF to investigate social media. Our participants were actively recruited from a CF clinic and during inpatient admissions, which resulted in a study population more representative of the CF community at our large, urban CF center. However, these findings may not be representative of all AYA with CF.

\section{Future Directions}

Our study suggests that although AYA with CF do not routinely use existing social media platforms for health-related behaviors, they do express interest in harnessing social media platforms for improving care delivery, accessing social support, and improving therapy adherence. The COVID-19 pandemic created psychosocial challenges for youth with chronic disease, which have implications for mental health and social supports [41]. Likewise, the pandemic also allowed for rapid-cycle digital advances in health care delivery [42] (eg, the popularization of the use of video-based applications for routine clinical communication). Many social media applications currently integrate video-based functions for users. This may allow for synchronous communication between people/care teams using videoconferencing rooms on Facebook or messaging/video calling features on WhatsApp, Facebook Messenger, or Google Duo. In addition, asynchronous communication may also have utility by posting recordings using Facebook Live or Instagram Live, or posting video stories (a feature of many social media platforms) for others as a form of encouragement or as a reminder. These features may have utility as a means for providing group-based support, facilitating accountability groups, or fostering socialization between AYA with CF and warrant further investigation. Additional considerations should be given to exploring the perceptions surrounding social media platform integration with the CF multidisciplinary team and routine clinical care, privacy concerns, and the implications of social determinants of health on social media use.

Finally, additional insight is needed to characterize baseline social isolation in this population and the desired modalities for support (individual video chats, messaging functionality, group video meetings, etc). It would be interesting to assess the use of social media and patients' reported sense of social isolation. For example, do AYA with CF who use social media have a lower sense of social isolation compared to those who do not use social media? Are there differences based on the type of social media modality used? Does gender have an impact on the sense of social isolation? Addressing social isolation is important as a possible means to improve self-care, adherence, and health outcomes. The implications are likely relevant for other chronic illnesses.

In conclusion, our study highlights the possible utility of social media platforms as an innovative intervention for improving health care delivery, social support, and treatment adherence. Overall, gaining insight from AYA with CF during any kind of intervention development will be critical to ensure effectiveness and improving value.

\section{Acknowledgments}

This project was supported by the Cystic Fibrosis Foundation Clinical Fellow Award (PERKIN17B0). 


\section{Authors' Contributions}

RCP coordinated and supervised data collection, carried out statistical analysis, and drafted the initial manuscript. RG and KR collected data and reviewed/revised the manuscript. LB conceptualized the study, designed the data collection instrument, and reviewed/revised the manuscript. GSS conceptualized the study, supervised the design of the data collection instrument, assisted with statistical analysis, and reviewed/revised the manuscript. All authors approved the final manuscript as submitted and agree to be accountable for all aspects of the work.

\section{Conflicts of Interest}

None declared.

\section{Multimedia Appendix 1}

Social media survey battery.

[DOCX File, 24 KB-Multimedia Appendix 1]

\section{References}

1. Cystic Fibrosis Foundation Patient Registry 2019 Annual Data Report. Cystic Fibrosis Foundation. URL: https://www. cff.org/Research/Researcher-Resources/Patient-Registry/2019-Patient-Registry-Annual-Data-Report.pdf [accessed 2020-02-20]

2. Bishay LC, Sawicki GS. Strategies to optimize treatment adherence in adolescent patients with cystic fibrosis. Adolesc Health Med Ther 2016;7:117-124 [FREE Full text] [doi: 10.2147/AHMT.S95637] [Medline: 27799838]

3. Cystic Fibrosis Foundation, Borowitz D, Robinson KA, Rosenfeld M, Davis SD, Sabadosa KA, et al. Cystic Fibrosis Foundation evidence-based guidelines for management of infants with cystic fibrosis. J Pediatr 2009 Dec;155(6 Suppl):S73-S93 [FREE Full text] [doi: 10.1016/j.jpeds.2009.09.001] [Medline: 19914445]

4. Lahiri T, Hempstead SE, Brady C, Cannon CL, Clark K, Condren ME, et al. Clinical Practice Guidelines From the Cystic Fibrosis Foundation for Preschoolers With Cystic Fibrosis. Pediatrics 2016 Apr;137(4):1-26. [doi: 10.1542/peds.2015-1784] [Medline: 27009033]

5. Yankaskas JR, Marshall BC, Sufian B, Simon RH, Rodman D. Cystic fibrosis adult care: consensus conference report. Chest 2004 Jan;125(1 Suppl):1S-39S. [doi: 10.1378/chest.125.1 suppl.1s] [Medline: 14734689]

6. George M, Rand-Giovannetti D, Eakin MN, Borrelli B, Zettler M, Riekert KA. Perceptions of barriers and facilitators: self-management decisions by older adolescents and adults with CF. J Cyst Fibros 2010 Dec;9(6):425-432 [FREE Full text] [doi: 10.1016/j.jcf.2010.08.016] [Medline: 20846910]

7. Sawicki GS, Heller KS, Demars N, Robinson WM. Motivating adherence among adolescents with cystic fibrosis: youth and parent perspectives. Pediatr Pulmonol 2015 Feb;50(2):127-136 [FREE Full text] [doi: 10.1002/ppul.23017] [Medline: 24616259]

8. Sawicki GS, Ostrenga J, Petren K, Fink AK, D'Agostino E, Strassle C, et al. Risk Factors for Gaps in Care during Transfer from Pediatric to Adult Cystic Fibrosis Programs in the United States. Ann Am Thorac Soc 2018 Feb;15(2):234-240. [doi: 10.1513/AnnalsATS.201705-3570C] [Medline: 29220199]

9. Roehrer E, Cummings E, Beggs S, Turner P, Hauser J, Micallef N, et al. Pilot evaluation of web enabled symptom monitoring in cystic fibrosis. Inform Health Soc Care 2013 Dec;38(4):354-365. [doi: 10.3109/17538157.2013.812646] [Medline: $\underline{23957685]}$

10. Govan JR, Brown PH, Maddison J, Doherty CJ, Nelson JW, Dodd M, et al. Evidence for transmission of Pseudomonas cepacia by social contact in cystic fibrosis. Lancet 1993 Jul 03;342(8862):15-19. [doi: 10.1016/0140-6736(93)91881-1] [Medline: 7686239$]$

11. Saiman L, Siegel JD, LiPuma JJ, Brown RF, Bryson EA, Chambers MJ, Cystic Fibrous Foundation, Society for Healthcare Epidemiology of America. Infection prevention and control guideline for cystic fibrosis: 2013 update. Infect Control Hosp Epidemiol 2014 Aug;35(S1):S1-S67. [doi: 10.1086/676882] [Medline: 25025126]

12. Wong CA, Merchant RM, Moreno MA. Using social media to engage adolescents and young adults with their health. Healthc (Amst) 2014 Dec;2(4):220-224 [FREE Full text] [doi: 10.1016/j.hjdsi.2014.10.005] [Medline: 25984444]

13. Rudolf I, Pieper K, Nolte H, Junge S, Dopfer C, Sauer-Heilborn A, et al. Assessment of a Mobile App by Adolescents and Young Adults With Cystic Fibrosis: Pilot Evaluation. JMIR mHealth uHealth 2019 Nov 21;7(11):e12442. [doi: $10.2196 / 12442]$

14. Fleming JN, Taber DJ, McElligott J, McGillicuddy JW, Treiber F. Mobile Health in Solid Organ Transplant: The Time Is Now. Am J Transplant 2017 Sep;17(9):2263-2276. [doi: 10.1111/ajt.14225] [Medline: 28188681]

15. McKenzie RB, Berquist WE, Foley MA, Park KT, Windsheimer JE, Litt IF. Text Messaging Improves Participation in Laboratory Testing in Adolescent Liver Transplant Patients. J Particip Med 2015;7:1-15 [FREE Full text] [Medline: 26213633] 
16. McGillicuddy JW, Gregoski MJ, Weiland AK, Rock RA, Brunner-Jackson BM, Patel SK, et al. Mobile Health Medication Adherence and Blood Pressure Control in Renal Transplant Recipients: A Proof-of-Concept Randomized Controlled Trial. JMIR Res Protoc 2013;2(2):e32 [FREE Full text] [doi: 10.2196/resprot.2633] [Medline: 24004517]

17. DeVito Dabbs A, Song MK, Myers BA, Li R, Hawkins RP, Pilewski JM, et al. A Randomized Controlled Trial of a Mobile Health Intervention to Promote Self-Management After Lung Transplantation. Am J Transplant 2016 Jul;16(7):2172-2180 [FREE Full text] [doi: 10.1111/ajt.13701] [Medline: 26729617]

18. Magid DJ, Olson KL, Billups SJ, Wagner NM, Lyons EE, Kroner BA. A pharmacist-led, American Heart Association Heart360 Web-enabled home blood pressure monitoring program. Circ Cardiovasc Qual Outcomes 2013 Mar 1;6(2):157-163 [FREE Full text] [doi: 10.1161/CIRCOUTCOMES.112.968172] [Medline: 23463811]

19. Margolis KL, Asche SE, Bergdall AR, Dehmer SP, Groen SE, Kadrmas HM, et al. Effect of home blood pressure telemonitoring and pharmacist management on blood pressure control: a cluster randomized clinical trial. JAMA 2013 Jul 3;310(1):46-56 [FREE Full text] [doi: 10.1001/jama.2013.6549] [Medline: 23821088]

20. Weintraub A, Gregory D, Patel AR, Levine D, Venesy D, Perry K, et al. A multicenter randomized controlled evaluation of automated home monitoring and telephonic disease management in patients recently hospitalized for congestive heart failure: the SPAN-CHF II trial. J Card Fail 2010 Apr;16(4):285-292. [doi: 10.1016/j.cardfail.2009.12.012] [Medline: 20350694]

21. Quinn CC, Clough SS, Minor JM, Lender D, Okafor MC, Gruber-Baldini A. WellDoc mobile diabetes management randomized controlled trial: change in clinical and behavioral outcomes and patient and physician satisfaction. Diabetes Technol Ther 2008 Jun;10(3):160-168. [doi: 10.1089/dia.2008.0283] [Medline: 18473689]

22. Chow CK, Redfern J, Hillis GS, Thakkar J, Santo K, Hackett ML, et al. Effect of Lifestyle-Focused Text Messaging on Risk Factor Modification in Patients With Coronary Heart Disease: A Randomized Clinical Trial. JAMA 2015;314(12):1255-1263. [doi: 10.1001/jama.2015.10945] [Medline: 26393848]

23. Bhavnani SP, Narula J, Sengupta PP. Mobile technology and the digitization of healthcare. Eur Heart J 2016 Dec 07;37(18):1428-1438 [FREE Full text] [doi: 10.1093/eurheartj/ehv770] [Medline: 26873093]

24. Marciel KK, Saiman L, Quittell LM, Dawkins K, Quittner AL. Cell phone intervention to improve adherence: cystic fibrosis care team, patient, and parent perspectives. Pediatr Pulmonol 2010 Feb;45(2):157-164 [FREE Full text] [doi: 10.1002/ppul.21164] [Medline: 20054860]

25. Hilliard ME, Hahn A, Ridge AK, Eakin MN, Riekert KA. User Preferences and Design Recommendations for an mHealth App to Promote Cystic Fibrosis Self-Management. JMIR mHealth uHealth 2014;2(4):e44 [FREE Full text] [doi: 10.2196/mhealth.3599] [Medline: 25344616]

26. Francis J, Cross D, Schultz A, Armstrong D, Nguyen R, Branch-Smith C. Developing a smartphone application to support social connectedness and wellbeing in young people with cystic fibrosis. J Cyst Fibros 2020 Mar;19(2):277-283. [doi: 10.1016/j.jcf.2019.12.011] [Medline: $\underline{\text { 31917112] }}$

27. Cook NS, Kostikas K, Gruenberger J, Shah B, Pathak P, Kaur VP, et al. Patients' perspectives on COPD: findings from a social media listening study. ERJ Open Res 2019 Feb;5(1):1-10. [doi: 10.1183/23120541.00128-2018] [Medline: 30775374$]$

28. Cherrez OI, Baptist A, Calderon J. Preferences of using social media among COPD patients in Latinoamerica. European Respiratory Society 2016;48(Suppl 60):12. [doi: 10.1183/13993003.congress-2016.pa2894]

29. Apperson A, Stellefson M, Paige SR, Chaney BH, Chaney JD, Wang MQ, et al. Facebook Groups on Chronic Obstructive Pulmonary Disease: Social Media Content Analysis. Int J Environ Res Public Health 2019 Oct 09;16(20):1-17 [ㅌREE Full text] [doi: 10.3390/ijerph16203789] [Medline: 31600907]

30. Stellefson M, Paige SR, Alber JM, Stewart M. COPD360social Online Community: A Social Media Review. Health Promotion Practice 2018 Jun 08;19(4):489-491. [doi: 10.1177/1524839918779567]

31. Welch L, Orlando R, Lin SX, Vassilev I, Rogers A. Findings from a pilot randomised trial of a social network self-management intervention in COPD. BMC Pulm Med 2020 Jun 08;20(1):162 [FREE Full text] [doi: 10.1186/s12890-020-1130-1] [Medline: $\underline{32513163]}$

32. Dale C, Reid N, Cox K, Jones A, Williams H, Shawcross A, et al. Using social media to improve communication with people with cystic fibrosis. ERJ Open Res 2016 Jan;2(1):1-3 [FREE Full text] [doi: 10.1183/23120541.00015-2016] [Medline: 27730164]

33. Moola F. The complexities of contagion: The experience of social isolation among children and youth living with cystic fibrosis in Canada. J Child Health Care 2018 Dec;22(4):631-645. [doi: 10.1177/1367493518767784] [Medline: 29614879]

34. Shuman DM. An Assessment of the Cystic Fibrosis Community's Use of Social Media as a Community and Medical Resource. eScholarship. 2017. URL: https://escholarship.org/uc/item/8mw9t844 [accessed 2020-12-25]

35. Bishay LC, Nelson E, Goldmann D, Weitzman E, Sawicki GS. Pediatric Pulmonology. Pediatr Pulmonol 2017 Sep 19;52(S47):S1-S82. [doi: 10.1002/ppul.23837]

36. Harris PA, Taylor R, Thielke R, Payne J, Gonzalez N, Conde JG. Research electronic data capture (REDCap)--a metadata-driven methodology and workflow process for providing translational research informatics support. J Biomed Inform 2009 Apr;42(2):377-381 [FREE Full text] [doi: 10.1016/j.jbi.2008.08.010] [Medline: 18929686] 
37. Harris PA, Taylor R, Minor BL, Elliott V, Fernandez M, O'Neal L, REDCap Consortium. The REDCap consortium: Building an international community of software platform partners. J Biomed Inform 2019;95:103208 [FREE Full text] [doi: 10.1016/j.jbi.2019.103208] [Medline: $\underline{31078660]}$

38. Flewelling KD, Sellers DE, Sawicki GS, Robinson WM, Dill EJ. Social support is associated with fewer reported symptoms and decreased treatment burden in adults with cystic fibrosis. J Cyst Fibros 2019 Jul;18(4):572-576 [FREE Full text] [doi: 10.1016/j.jcf.2019.01.013] [Medline: $\underline{30772245]}$

39. Flewelling KD, Sellers DE, Sawicki GS, Robinson WM, Dill EJ. Male gender and unemployment are associated with lower levels of perceived social support in adults with cystic fibrosis. J Psychosom Res 2019 Dec;127:109858. [doi: 10.1016/j.jpsychores.2019.109858] [Medline: $\underline{\text { 31706070] }}$

40. Hausmann JS, Touloumtzis C, White MT, Colbert JA, Gooding HC. Adolescent and Young Adult Use of Social Media for Health and Its Implications. J Adolesc Health 2017 Jun;60(6):714-719. [doi: 10.1016/j.jadohealth.2016.12.025] [Medline: 28259620]

41. Serlachius A, Badawy SM, Thabrew H. Psychosocial Challenges and Opportunities for Youth With Chronic Health Conditions During the COVID-19 Pandemic. JMIR Pediatr Parent 2020 Oct 12;3(2):e23057 [FREE Full text] [doi: 10.2196/23057] [Medline: 33001834$]$

42. Badawy SM, Radovic A. Digital Approaches to Remote Pediatric Health Care Delivery During the COVID-19 Pandemic: Existing Evidence and a Call for Further Research. JMIR Pediatr Parent 2020 Jun 25;3(1):e20049 [FREE Full text] [doi: 10.2196/20049] [Medline: $\underline{32540841]}$

\author{
Abbreviations \\ AYA: adolescents and young adults \\ CF: cystic fibrosis \\ mHealth: mobile health \\ ppFEV1: percent predicted forced expiratory volume in 1 second
}

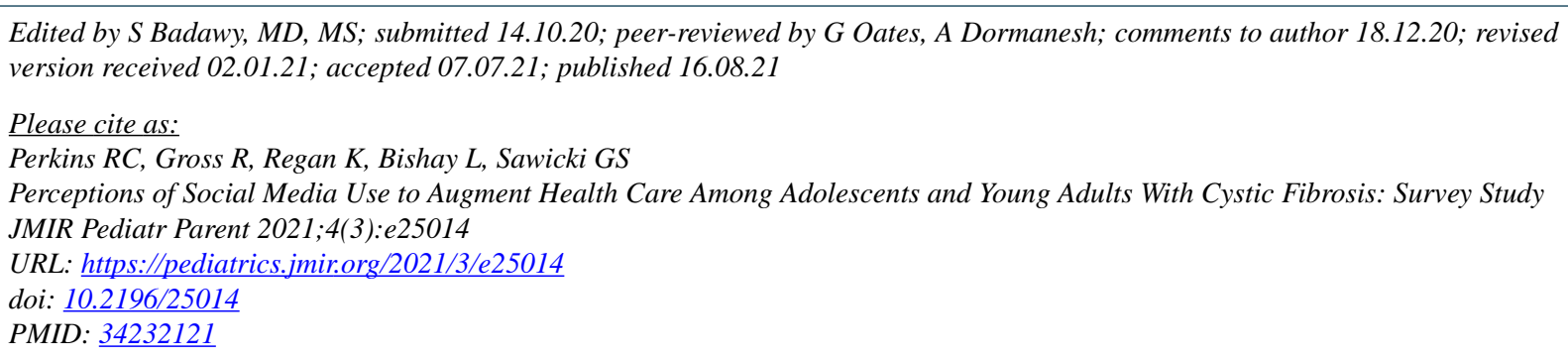

CRyan C Perkins, Rachel Gross, Kayla Regan, Lara Bishay, Gregory S Sawicki. Originally published in JMIR Pediatrics and Parenting (https://pediatrics.jmir.org), 16.08.2021. This is an open-access article distributed under the terms of the Creative Commons Attribution License (https://creativecommons.org/licenses/by/4.0/), which permits unrestricted use, distribution, and reproduction in any medium, provided the original work, first published in JMIR Pediatrics and Parenting, is properly cited. The complete bibliographic information, a link to the original publication on https://pediatrics.jmir.org, as well as this copyright and license information must be included. 